\title{
Mechanical Behavior of Damaged H-Section Steel Structure
}

\author{
Xibing Hu, ${ }^{1}$ Rui Chen $\mathbb{D}^{1},{ }^{1}$ Yuxuan Xiang, ${ }^{2}$ Yafang Chen, ${ }^{3}$ and Qingshan $\mathrm{Li}^{4}$ \\ ${ }^{1}$ College of Civil Engineering, Central South University of Forestry and Technology, Changsha 410004, China \\ ${ }^{2}$ Changsha Engineering and Research Institute Ltd. of Nonferrous Metallurgy, Changsha 410004, China \\ ${ }^{3}$ Hunan Architectural Design Institute Limited Company, Changsha 410004, China \\ ${ }^{4}$ Changsha Sanyuan Steel Structure Co. Ltd, Changsha 410004, China \\ Correspondence should be addressed to Rui Chen; chenrui921@foxmail.com
}

Received 11 December 2019; Revised 21 April 2021; Accepted 6 May 2021; Published 29 May 2021

Academic Editor: Dimitris Rizos

Copyright (c) 2021 Xibing Hu et al. This is an open access article distributed under the Creative Commons Attribution License, which permits unrestricted use, distribution, and reproduction in any medium, provided the original work is properly cited.

\begin{abstract}
Steel structures are usually damaged by disasters. According to the influence law of the damage on the elastic modulus of steel obtained by the mechanical test of damaged steel, the average elastic moduli of H-section steel members were analyzed. The equations for calculating the average elastic moduli of damaged $\mathrm{H}$-section steel members at different damage degrees were obtained. By using the analytical cross-sectional method, the cross-sectional $M-\Phi-P$ relationships and the dimensionless parameter equations of the $\mathrm{H}$-sections in the full-sectional elastic distribution, single-sided plastic distribution, and double-sided plastic distribution were derived. On the basis of the cross-sectional $M-\Phi-P$ relationships and dimensionless parameters of actual steel members, the approximate calculation equations for the damaged cross sections were obtained. The Newmark method was used to analyze the deformation of damaged steel columns. Analytical results show good agreement with the test results. The equations and methods proposed in this study have high computational accuracy, and these can be applied to the cross-sectional $M-\Phi-P$ relationships and deformation calculation of damaged steel members.
\end{abstract}

\section{Introduction}

Natural disasters or other factors often lead to local damage or total damage of steel members. Whether damaged members can meet the bearing capacity and stiffness requirements will directly affect the safety and reliability of damaged steel structures. A large number of scholars around the world have conducted numerous researches on this subject.

Ge [1] identified the element damage of a nine-story steel frame structure through the finite element model of the undamaged structure and the modal parameters of the damaged structure (mode shape and frequency). The location of damage was determined by residual force method, and the degree of damage was identified by using matrix condensation method combined with proportional damage model. Gorl [2] used finite element method to identify the damage location and degree of a two-story steel frame structure, in which the degree of structural damage was identified on the basis of the change in stiffness before and after the structural damage and the experimental modal data of the damaged structure. Fell [3] used the microscopic damage model to predict the fractures of steel struts in concentrically braced frames leading to structural failure. Huajing [4] developed a multiscale fatigue damage model in order to better understand the fatigue mechanisms of steel structures working under high temperature. In the developed model, the fatigue damage of metallic materials due to the collective behavior of microcracks is quantified by using the generalized self-consistent method. Neves [5] has observed that the stiffness of a cracked beam is less than the stiffness of an uncracked beam and that condition was reflected in the decrease of the natural frequencies of the cracked beam and in its free dynamic response. Altunışık [6] conducted modal parameter identification and vibrationbased damage detection by using the finite element method and experimental measurements of multiple cracked cantilever beams with hollow circular sections. They discovered that cracks strongly affect the natural frequencies of the beam; at the cracked section, the frequencies decreased 
nonmonotonically in response to the reduction in flexural stiffness of the beam at the damaged section. Chinka [7] observed that modal analysis is used easily to observe the effect of cracks on the natural frequencies and mode shapes for a range of crack locations and crack depth. Tao [8] developed a method that can be used to sense and localize damage-induced nonlinearities in structures under seismic excitation. The nonlinearity behavior of the structure, such as opening and closing of the cracks in concrete and yielding of steel, can be noticed in the real structure. Yue [9] analyzed the fatigue performance of carbon fiber-reinforced polymer (CFRP) reinforced steel crane girders by experiments and studied the influence of CFRP on the stress concentration. Tominaga et al. [10] studied the fatigue improvement effect of ultrasonic impact treatment method by analyzing both the strengthened in-plane gusset and out-of-plane gusset detail of steel crane runway girders. Shen [11] studied the mechanical behavior of Q345 GJ steel, including monotonic loading behavior, hysteresis loading behaviors, and energy dissipation capacity. Based on the cyclic behavior of GJ series steel, a modified cumulative damage model was recommended. Fei [12] presented a practical calibration for the ductile damage model of S355 and high-strength steel S690Q, S700 MC, and S960Q based on tensile coupon test results. A combined linear and power expression is adopted to calibrate the postnecking damaged stress-strain relations of the investigated steels, upon which the undamaged stressstrain relations are estimated further. Rabczuk et al. [13] presented an approach for modelling discrete cracks in meshfree methods. In this method, the crack can be arbitrarily oriented, but its growth is represented discretely by activation of crack surfaces at individual particles, so no representation of the crack's topology is needed. The model is applied to several $2 \mathrm{D}$ problems and compared to experimental data. Furthermore, Rabczuk et al. [14] also presented a three-dimensional meshfree method for modelling arbitrary crack initiation and crack growth in reinforced concrete structure. This meshfree method is based on a partition of unity concept and formulated for geometrically nonlinear problems. The crack kinematics are obtained by enriching the solution space in order to capture the correct crack kinematics. A cohesive zone model is used after crack initiation. The reinforcement modelled by truss or beam elements is connected by a bond model to the concrete. This method is applied to model the fracture of several reinforced concrete structures. Hongping [15] presented an innovative mechanical impedance-based technique to monitor the development of corrosion damage on steel structure, which is different from the traditional admittance- (inverse of impedance-) based EMI technique. The experimental results indicate that structural mechanical impedance is sensitive to corrosion damage, but the detecting range is limited. The real part of SMI can be adopted for an effective indicator of steel structural corrosion damage. The proposed technique is found to be effective in steel structural corrosion damage detection. Sajjad [16] addressed the strain ageing effects on the mechanical properties of the partially damaged structural mild steel. The stress-strain relation of partially damaged mild-steel material incorporating strain ageing effects is expressed by calibrating the parameters of Ramberg-Osgood model. Mohammad [17] studied the performance of H-section steel columns investigated under blast loads. $\mathrm{H}$-section steel columns subjected to blast loads are numerically investigated, so as to derive practical formulations for damage evaluation assessment. The strategy is based on parametric finite element (FE) models (with up to 5600 configurations), validated towards experiments, and used as an extensive data bank for further elaboration via Gene Expression Programming. Mohammad [18] also investigated the dynamic behavior of steel columns under blast pressures, and the results show that the cross-sectional shape only slightly affects the global dynamic behavior of steel columns.

Currently, only few studies on the mechanical properties of damaged steel beams and columns have been done. In this study, the calculation method of the average elastic modulus of the damaged cross section was studied according to the influence law of damage on the elastic modulus of steel. The $M-\Phi-P$ relationships of $\mathrm{H}$-section steel members were calculated by using the analytical cross-sectional method, and the deformations of damaged steel columns were analyzed by applying the Newmark method. The feasibility of these methods was verified by comparison with the test results. The damage of members with other section features can also refer to the method in this paper.

\section{Mechanical Properties Test of Damaged Steel}

The mechanical properties of damaged steel were acquired by the tensile coupon tests. The initial elastic modulus of the steel is $E_{0}$. The specimens were unloaded when plastic deformation occurred in different degrees, and the slope of unloading line was recorded as unloading elastic modulus $E^{\prime}$. Then a secondary loading test is performed on the damaged specimens, and the slope of loading line was recorded as loading elastic modulus $\check{E}$. Through this method, the interaction between the unloading modulus and the loading elastic modulus during the secondary loading and the existing plastic deformation of the steel can be obtained.

2.1. Specimen Design. In this paper, Q345 steel samples are divided into 8 groups, and each group has 3 specimens. The size of the specimen is shown in Figure 1.

2.2. The Test Process. The first group of specimens was subjected to uniaxial tensile test in the testing machine, and when the specimens reached the ultimate strength, the loading ended. It is found that the deformation at the end of the flow molding phase (the end point of the yield stage) is about $0.8 \mathrm{~mm}$, and that at the end of the strengthening phase is about $8.4 \mathrm{~mm}$.

According to the results of the first set of test data, the deformation control values of the second group to the eighth group were $0.8 \mathrm{~mm}, 2 \mathrm{~mm}, 3 \mathrm{~mm}, 4 \mathrm{~mm}, 5 \mathrm{~mm}, 7 \mathrm{~mm}$, and $8.4 \mathrm{~mm}$, respectively.

The second to eighth groups of specimens were loaded to the deformation control value, then unloaded, and then loaded into each group of specimens to destroy. The test 


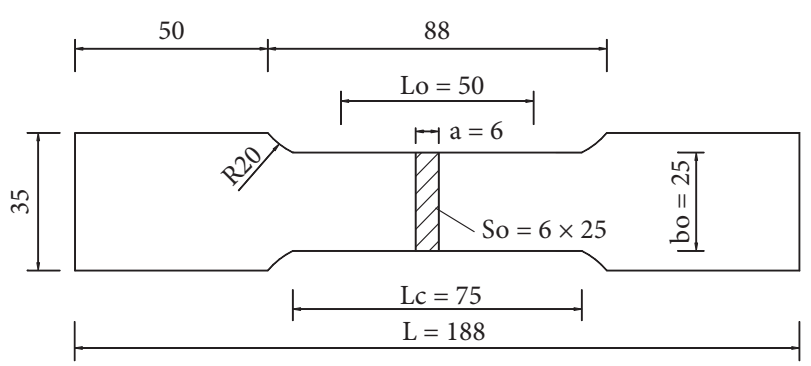

Figure 1: Tensile specimens.

process and the contrast of the deformation before and after tensile test are shown in Figures 2 and 3, respectively.

2.3. Results of the Test. The tensile test results of 8 groups of specimens are shown in Table 1.

As can be seen from Table 1, the average modulus of elasticity is about $185 \mathrm{GPa}$, yield strength is about $350 \mathrm{MPa}$, and ultimate strength is about $520 \mathrm{MPa}$ without damage.

2.4. Test Data Analysis. The relationship between the initial elastic modulus, the unloading elastic modulus, and the loading elastic modulus and the deformation control value of the eight groups of specimens is plotted into curves, as shown in Figure 4.

As can be seen from Figure 4, the loading elastic modulus of Q345 steel with different plastic deformation under secondary loading is related to the control value of plastic deformation. The larger the deformation control value, the smaller the values of loading elastic modulus and unloading elastic modulus. The test results are consistent with the theory that damage leads to the decrease of elastic modulus of steel [19].

The uniaxial tensile test of damaged Q235 steel has been carried out in [20] and is compared with the test results of Q345 steel in this paper, as shown in Figure 5. For comparative analysis, the ratio of loading elastic modulus to initial elastic modulus $\left(e=\check{\mathrm{E}} / \mathrm{E}_{0}\right)$ is adopted as longitudinal coordinates in Figure 5.

As can be seen from Figure 5, the loading modulus of Q235 and Q345 steel decreases with the increase of deformation control value, and the decrease of elastic modulus of Q235 steel is slightly higher than that of Q345 steel. When $\varepsilon \leq 0.19 \%$, the loading elastic modulus of Q345 steel is consistent with the initial elastic modulus. When $0.19 \% \leq \varepsilon \leq$ $1.6 \%$, the elastic modulus of Q345 steel begins to decrease rapidly. When $\varepsilon \geq 1.6 \%$, the elastic modulus of Q345 steel begins to decrease slowly. The curve parallel segment of Q235 steel is obviously longer than that of Q345 steel. When $\varepsilon$ reaches $1.6 \%$, the loading elastic modulus of Q235 steel begins to decrease rapidly, and the decrease of elastic modulus is obviously larger than that of Q345 steel. When $\varepsilon$ of steel reaches $4 \%$, the elastic modulus of Q235 steel begins to decrease slowly, and the decrease of elastic modulus of Q235 steel was larger than that of Q345 steel.

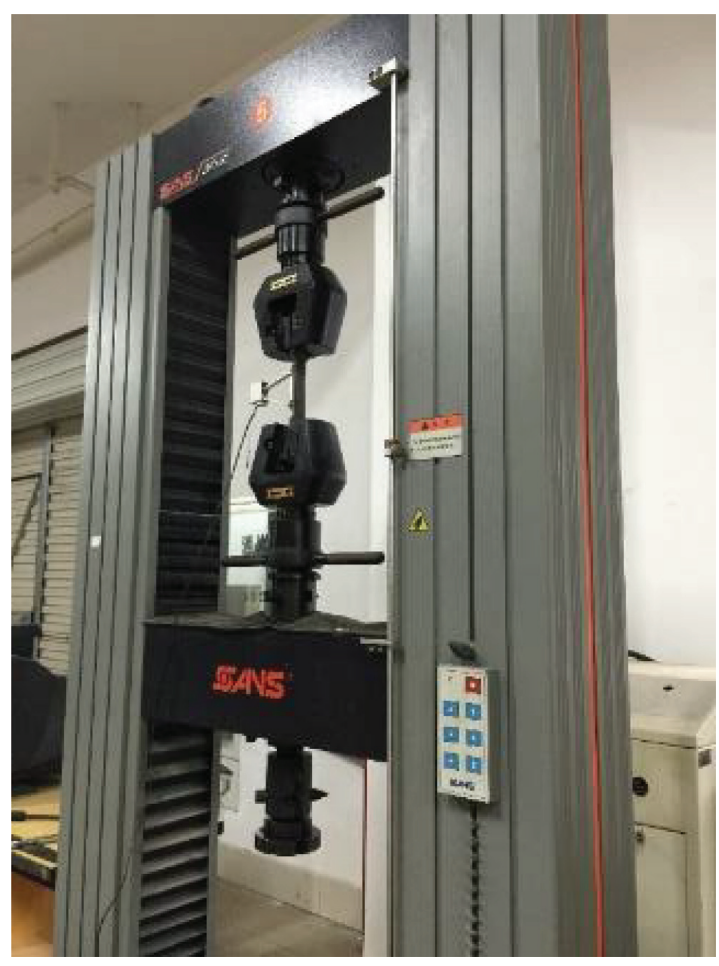

Figure 2: Universal material testing machine.

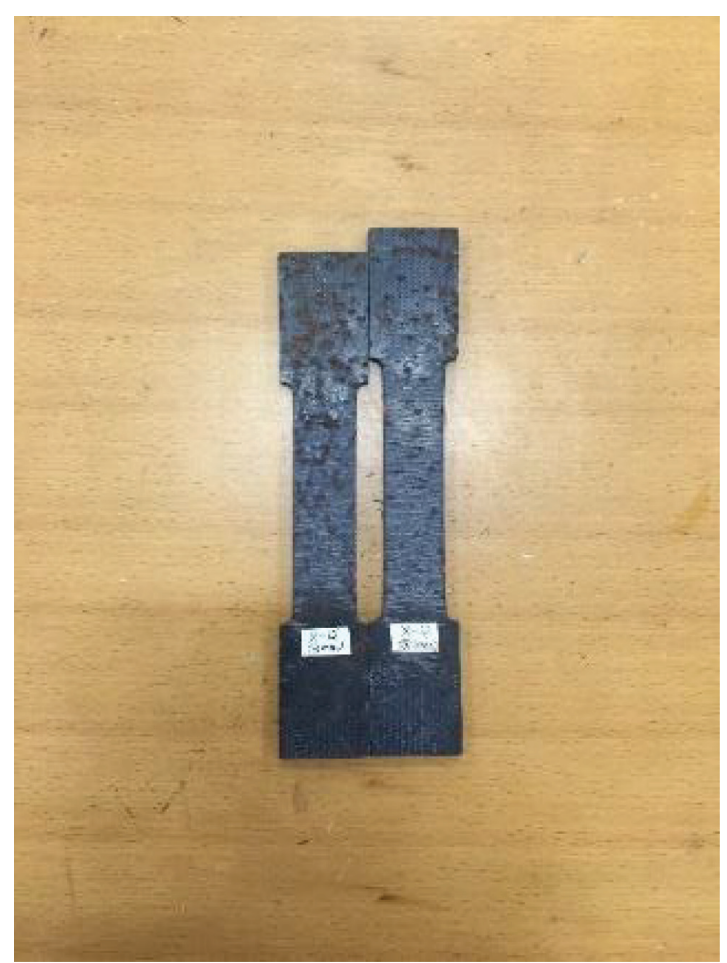

FIgUre 3: Contrast of elongation (initial elongation is $3 \mathrm{~mm}$ and $8.4 \mathrm{~mm})$.

The loading elastic modulus curve of Q345 steel in Figure 5 is fitted by multiline segment fitting. The fitting results are shown in Figure 6. 
TABle 1: Data of tensile test.

\begin{tabular}{|c|c|c|c|c|c|c|}
\hline \multicolumn{7}{|c|}{ Q345 steel plate test } \\
\hline $\begin{array}{l}\text { Group } \\
\text { number }\end{array}$ & $\begin{array}{l}\text { Specimen } \\
\text { number }\end{array}$ & $\begin{array}{l}\text { Initial deformation } \\
\qquad(\mathrm{mm})\end{array}$ & $\begin{array}{c}\text { Initial } \\
\text { strain (\%) }\end{array}$ & $\begin{array}{c}\text { Initial elastic } \\
\text { modulus } E_{0}(\mathrm{GPa})\end{array}$ & $\begin{array}{l}\text { Unloading elastic } \\
\text { modulus } E^{\prime}(\mathrm{GPa})\end{array}$ & $\begin{array}{l}\text { Loading elastic } \\
\text { modulus } \check{E}(\mathrm{GPa})\end{array}$ \\
\hline \multirow{3}{*}{$\begin{array}{l}\text { The first } \\
\text { group }\end{array}$} & $\mathrm{X}-01$ & 0 & 0 & 189.406 & -- & -- \\
\hline & $\mathrm{X}-02$ & 0 & 0 & 194.075 & -- & -- \\
\hline & $\mathrm{X}-03$ & 0 & 0 & $186 . .831$ & -- & -- \\
\hline \multirow{3}{*}{$\begin{array}{l}\text { The second } \\
\text { group }\end{array}$} & $\mathrm{X}-04$ & 0.8 & 1.6 & 189.914 & 152.243 & 159.828 \\
\hline & $\mathrm{X}-05$ & 0.8 & 1.6 & 176.957 & 157.844 & 161.121 \\
\hline & $\mathrm{X}-06$ & 0.8 & 1.6 & 190.728 & 155.084 & 157.661 \\
\hline \multirow{3}{*}{$\begin{array}{l}\text { The third } \\
\text { group }\end{array}$} & $\mathrm{X}-07$ & 2 & 4 & 180.096 & 148.282 & 148.913 \\
\hline & $\mathrm{X}-08$ & 2 & 4 & 184.590 & 151.591 & 168.217 \\
\hline & $\mathrm{X}-09$ & 2 & 4 & 194.798 & 150.475 & 152.643 \\
\hline \multirow{3}{*}{$\begin{array}{l}\text { The fourth } \\
\text { group }\end{array}$} & $\mathrm{X}-10$ & 3 & 6 & 205.387 & 142.254 & 147.342 \\
\hline & $\mathrm{X}-11$ & 3 & 6 & 175.724 & 134.118 & 137.034 \\
\hline & $\mathrm{X}-12$ & 3 & 6 & 193.402 & 136.921 & 151.378 \\
\hline \multirow{3}{*}{$\begin{array}{l}\text { The fifth } \\
\text { group }\end{array}$} & $\mathrm{X}-13$ & 4 & 8 & 182.236 & 133.788 & 134.963 \\
\hline & $\mathrm{X}-14$ & 4 & 8 & 191.110 & 135.149 & 138.170 \\
\hline & $\mathrm{X}-15$ & 4 & 8 & 174.076 & 141.097 & 148.569 \\
\hline \multirow{3}{*}{$\begin{array}{l}\text { The sixth } \\
\text { group }\end{array}$} & $X-16$ & 5 & 10 & 176.064 & 135.568 & 146.122 \\
\hline & $\mathrm{X}-17$ & 5 & 10 & 182.819 & 134.673 & 133.307 \\
\hline & $\mathrm{X}-18$ & 5 & 10 & 179.192 & 135.745 & 140.715 \\
\hline \multirow{3}{*}{$\begin{array}{l}\text { The seventh } \\
\text { group }\end{array}$} & X-19 & 7 & 14 & 207.494 & 120.060 & 121.416 \\
\hline & $X-20$ & 7 & 14 & 164.472 & 120.332 & 121.737 \\
\hline & $\mathrm{X}-21$ & 7 & 14 & 189.840 & 120.994 & 122.178 \\
\hline \multirow{3}{*}{$\begin{array}{l}\text { The eighth } \\
\text { group }\end{array}$} & $\mathrm{X}-22$ & 8.4 & 16.8 & 190.598 & 127.443 & 125.962 \\
\hline & $\mathrm{X}-23$ & 8.4 & 16.8 & 178.959 & 118.255 & 124.386 \\
\hline & $\mathrm{X}-24$ & 8.4 & 16.8 & 178.563 & 115.233 & 119.571 \\
\hline
\end{tabular}

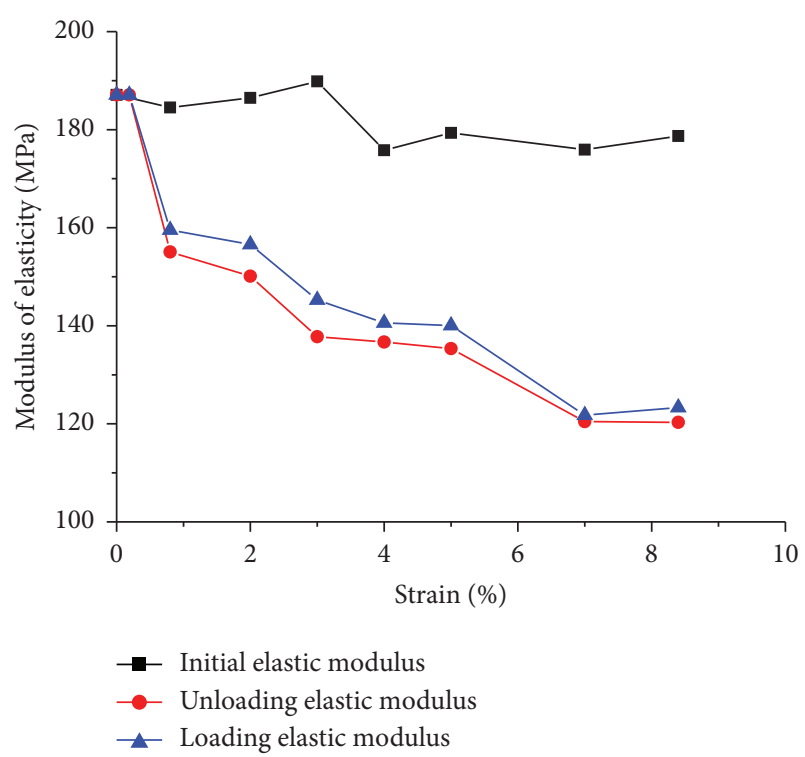

Figure 4: Comparison of elastic modulus during the three stages.

As can be seen from Figure 6, the fitting results are in good agreement with the original data. According to the test data, the change of elastic modulus of damaged Q345 steel under different damage degree can be obtained by taking the yield strength $\sigma_{\mathrm{y}}=350 \mathrm{MPa}$ and the initial elastic modulus $E_{0}=1.85 \times 105 \mathrm{MPa}$.

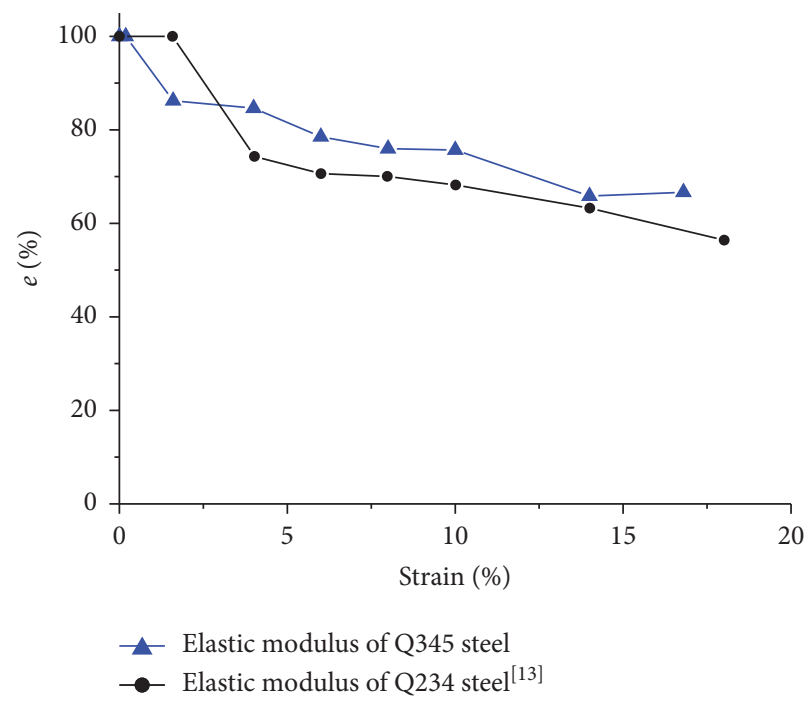

Figure 5: Comparison of elastic modulus.

when $0 \leq \varepsilon \leq 0.19 \% \check{\mathrm{E}}=\mathrm{E}_{0}$,

when $\quad 0.19 \% \leq \varepsilon \leq 1.6 \% \check{\mathrm{E}}=\frac{(100-8.6 \varepsilon}{100} \mathrm{E}_{0}$,

when $\quad 1.6 \% \leq \varepsilon \leq 16.8 \stackrel{\mathrm{E}}{\mathrm{E}}=\frac{(88.48-1.4 \varepsilon)}{100} \mathrm{E}_{0}$. 


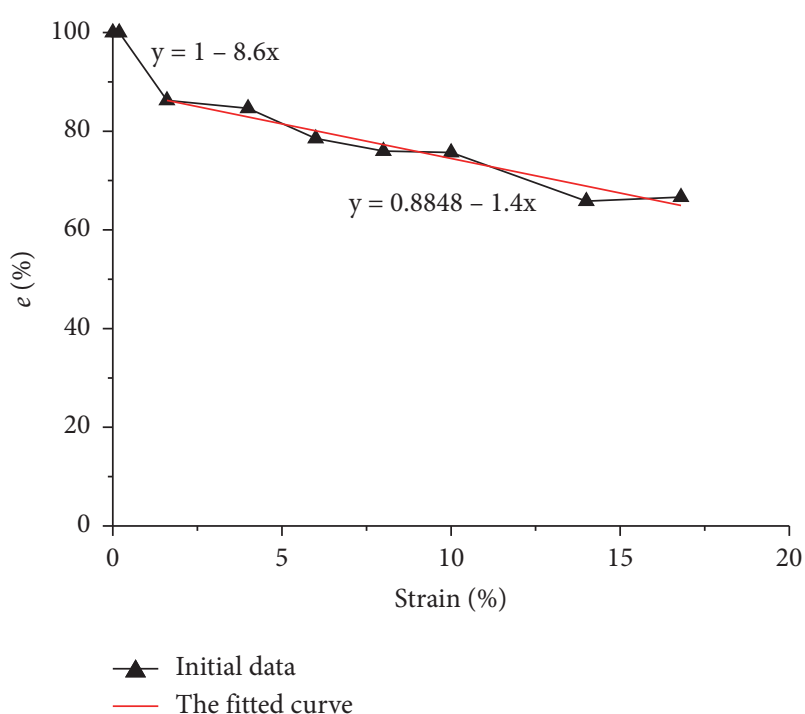

Figure 6: The percentage decline of elastic modulus in unloading stage.

\section{Average Elastic Modulus of Damaged Steel Cross Section}

The stress-strain relationship of steel in different part of the cross section changes greatly after the cross section of a steel member is damaged. Steel exhibits varying degrees of damage and under elastic stress state. To facilitate the calculation of ultimate bearing capacity and deformation, the average elastic modulus of damaged cross section is used to replace the elastic modulus of undamaged steel.

For the H-section, when the steel damage occurs only in the flange, partial flange damage does not cause a major change in the average elastic modulus of the entire cross section due to the thinness of the flange. Hence, this situation can be assumed as slight damage of the cross section. At this time, the average elastic modulus of the cross section is taken as the elastic modulus of the steel.

When the flange and part of the web of the cross section are damaged, the mechanical properties of the cross section change obviously. Hence, this situation can be assumed as general damage of the cross section.

When the damage degree is further aggravated, some strains in the damaged area of the section exceed $1.6 \%$; that is, serious damage is present in the section. Hence, this situation can be assumed as serious damage of the cross section.

Given that slight damage has minimal effect on the structure, this study only considers general damage and serious damage of the cross section. The distribution characteristics of loading elastic modulus of the generally damaged and seriously damaged cross section are shown in Figures 7 and 8, respectively.

$A_{1}=$ section area of undamaged zone, $A_{2}=$ section area of generally damaged zone, $A_{3}=$ section area of seriously damaged zone, $h_{1}=$ height of undamaged cross section, and $H=$ height of $\mathrm{H}$-shaped cross section.

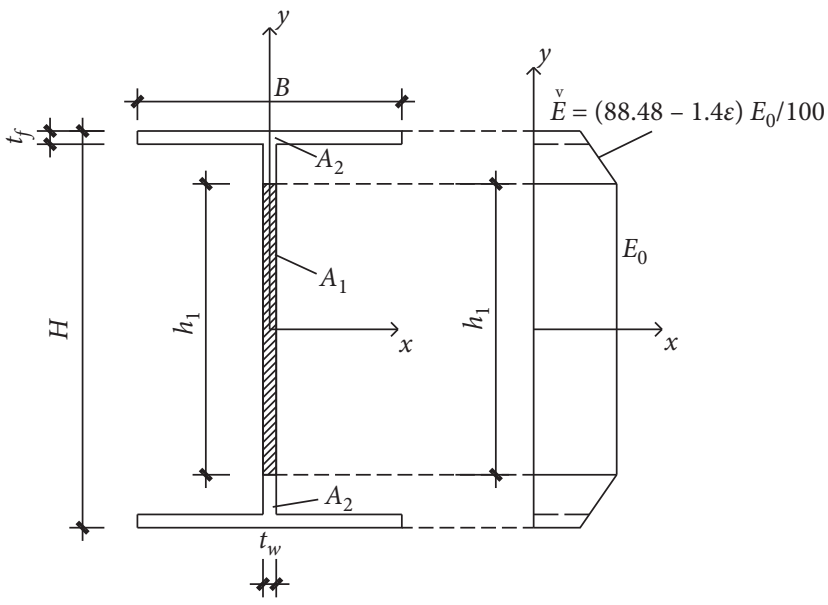

FIGURE 7: Distribution characteristics of elastic modulus of generally damaged cross section.

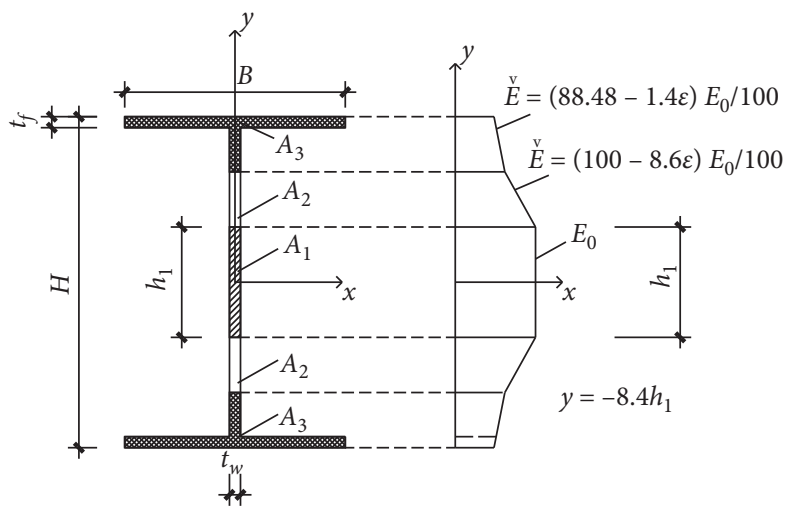

FIgURE 8: Distribution characteristics of elastic modulus of seriously damaged cross section.

To simplify the calculation, the following assumptions are made:

(1) Damage mainly refers to the phenomenon of partial or total yield of the cross section caused by the bending moment generated by the external load on the $\mathrm{H}$-section.

(2) Assumption plane section is satisfied after the cross section is damaged; that is, the cross section remains in the same plane after the cross section is damaged.

(3) The maximum strain value in the cross section is less than $18 \%$. The physical meaning of this assumption is that all materials in the damaged cross section have not overstepped the strengthening stage, and no serious nonuniform deformation occurs in the necking stage.

The strain distribution characteristics of generally damaged cross section and seriously damaged cross section can be obtained as shown in Figures 9 and 10, respectively.

According to the static equilibrium condition [21], the average elastic modulus in the damaged cross section can be expressed as 


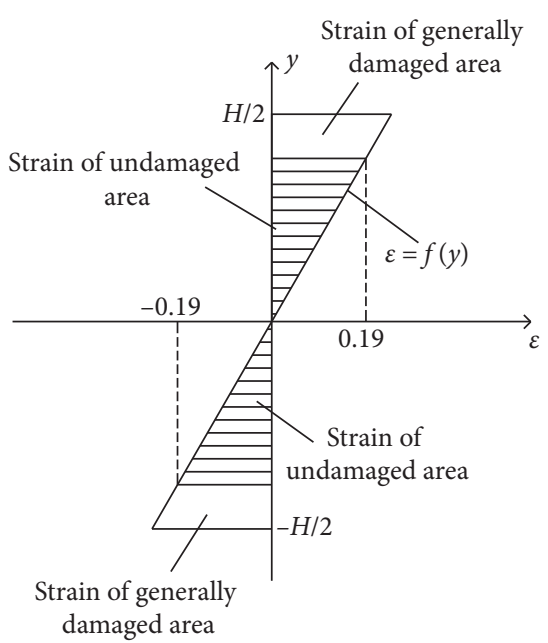

FIgURE 9: Strain distribution characteristics of generally damaged cross section.

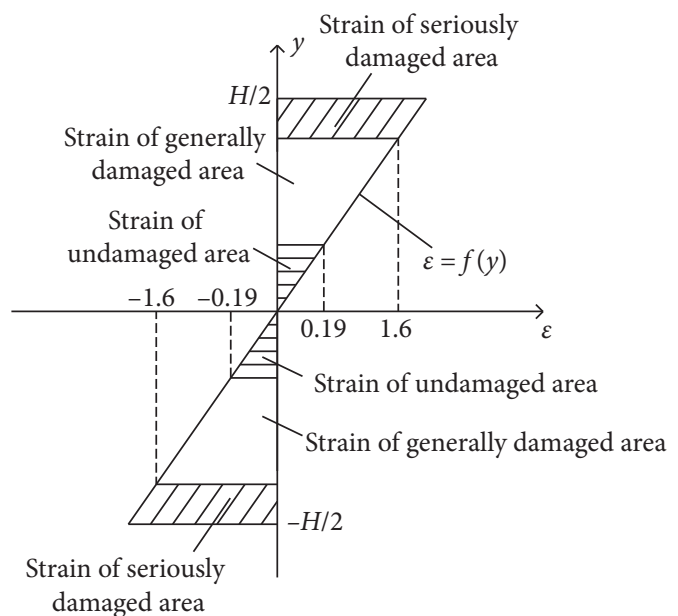

FIGURE 10: Strain distribution characteristics of seriously damaged cross section.

$$
\bar{E}=\frac{\int \check{E} \mathrm{dA}}{A},
$$

in which $\bar{E}=$ average elastic modulus of damaged cross section and $A=$ area of cross section.

After Equations (1)-(3) are substituted into Equation (4), the expressions for calculating the average elastic modulus of generally damaged cross section and seriously damaged cross section are obtained as follows:

Equation of generally damaged cross section:

$$
\begin{aligned}
\bar{E} & =\frac{\int \check{\mathrm{E}} \mathrm{dA}}{A}=\frac{\int E_{0} d A_{1}+\int \check{\mathrm{E}}_{1} d A_{2}}{A} \\
& =\frac{\int E_{0} d A_{1}+\int(1-0.086 \varepsilon) E_{0} d A_{2}}{A} \\
& =E_{0}-\frac{0.086 E_{0} \int f(y) d A_{2}}{A} .
\end{aligned}
$$

Equation of seriously damaged cross section:

$$
\bar{E}=E_{0}-\frac{0.1152 E_{0} A_{3}+0.086 E_{0} \int f(y) d A_{2}+0.014 E_{0} \int f(y) d A_{3}}{A} .
$$

\section{Moment-Curvature-Axis Force Relation of Damaged Cross Section of Member}

To study the mechanical properties of steel members subjected to interaction of axial force and bending moment, the relationships between bending moment $M$ and curvature $\Phi$ ( $M$ - $\Phi-P$ relationship) are used when the axial force $P$ is a fixed value. When the axial deformation of the member under axial force is large, the relationship between axial force $P$ and axial strain $\varepsilon$ ( $P-\varepsilon-M$ relationship) [22] of bending moment $M$ at a fixed value should be established. However, for general beam-column members, the bending deformation is usually larger than the axial deformation, and the mechanical properties of the cross section can be reflected by the relationship of moment-curvature-axial force $(M-\Phi-P$ relationship). To simplify the calculation, it is assumed that the stress-strain characteristics of the cross-sectional material are ideal elastic plastic, the stress-strain relationship of undamaged steel is the ideal elastic plastic model shown in curve 1 of Figure 11, and the stress-strain relationship of damaged steel is the ideal elastic plastic model shown in curve 2 of Figure 11.

Figure 12(a) shows the $\mathrm{H}$-shaped cross section of the steel member with axial force $P$ and moment $M$ acting on the cross section. The value of axial force $P$ is not fixed, as shown in Figure 12(b). Under the interaction of axial force and bending moment, three different stress states may be observed: full-sectional elastic stress distribution, single-sided plastic distribution, and double-sided plastic distribution, as shown in Figures 12(c)-12(e), respectively.

According to the static equilibrium condition, the axial force and bending moment of the cross section can be calculated as follows:

$$
\begin{gathered}
P=\int_{A} \sigma_{z} d A, \\
M=\int_{A} y \sigma_{z} d A .
\end{gathered}
$$

According to the method of material mechanics [23], the equations for calculating the bending moment, curvature, and axial force of the member cross section can be obtained as follows:

$$
\begin{aligned}
& M_{y}=\frac{I_{x} \sigma_{y}}{y_{\max }}, \\
& \Phi_{y}=\frac{M_{y}}{E I_{x}}=\frac{\sigma_{y}}{E y_{\max }}, \\
& P_{y}=\sigma_{y} A,
\end{aligned}
$$




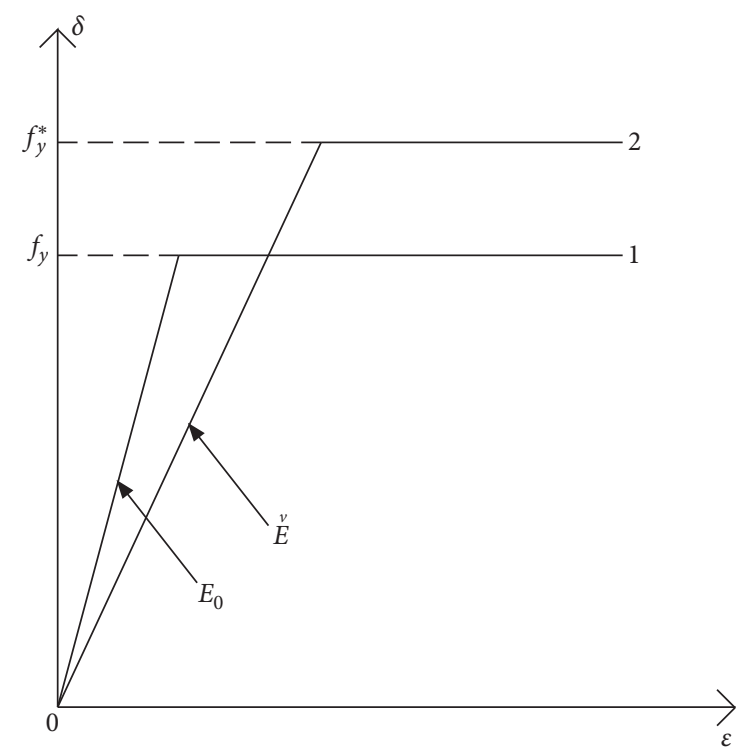

FIGURE 11: Stress-strain relationship of steel.

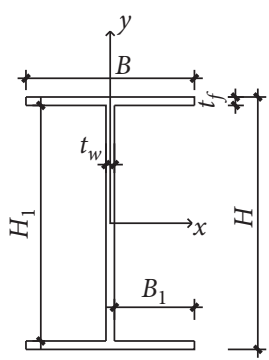

(a)

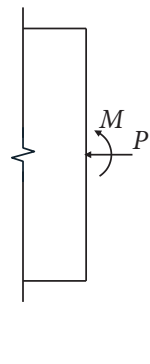

(b)

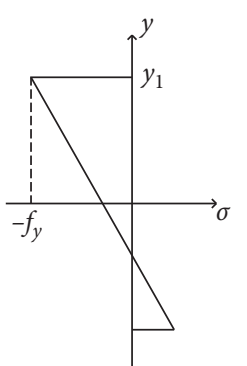

(c)

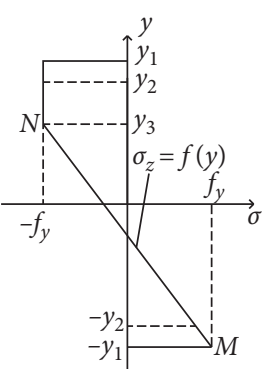

(d)

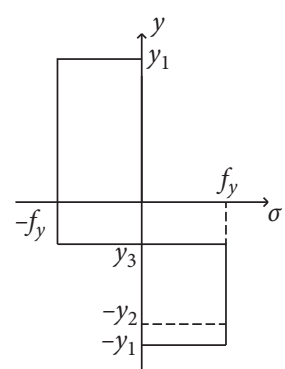

(e)

Figure 12: The characteristics of undamaged $\mathrm{H}$-shaped cross section when the value of axial force is constant: (a) H-shaped cross section; (b) internal force of the cross section; (c) full-sectional elastic stress distribution; (d) single-sided elastic stress distribution; (e) double-sided elastic stress distribution.

$$
I_{x}=\frac{B H^{3}-2 B_{1} H_{1}^{3}}{12}
$$

in which $I_{x}=$ inertia moment of the section to the neutral axis, $\sigma_{y}=$ yield stress, $y_{\max }=$ the ordinate of the farthest point from the neutral axis on the cross section, and $E=$ elastic modulus.

To facilitate numerical computation, the $M-\Phi-P$ relationship is expressed in dimensionless form. For this purpose, the following initial parameters and dimensionless variables are defined:

$$
\begin{gathered}
m=\frac{M}{M_{y}}, \\
\phi=\frac{\Phi}{\Phi_{y}}, \\
p=\frac{P}{P_{y}} .
\end{gathered}
$$

4.1. Full-Sectional Elastic Stress Distribution. When the axial force and moment are relatively small, under the interaction of the bending moment and the axial force, the maximum stress in the cross section of the member does not exceed the yield strength of the steel, and the whole cross section of the member is in the elastic state. The stress distribution of the section is shown in Figure 12(c). At this time, the ultimate stress state of the cross section is that the uppermost outer edge of the cross section reaches the yield stress $\sigma_{y}$ under the interaction of the compressive stress $\sigma m$ generated by the bending moment $M$ and the compressive stress $\sigma_{p}$ generated by the axial force $P$, and the yield stress at the lowermost outer edge has not yet reached the yield stress. Hence, it can be concluded as

$$
\sigma_{m}+\sigma_{p}=\sigma_{y} \longrightarrow \frac{M y_{\max }}{I_{x}}+\frac{P}{A}=\sigma_{y} \longrightarrow M=\frac{\left(\sigma_{y}-P / A\right) I_{x}}{y_{\max }}
$$

The following can be obtained from Equations (8a), (9a), and (10a): 


$$
m_{1}=\frac{M}{M_{y}}=\frac{\left(\sigma_{y}-P / A\right) I_{x} / y_{\max }}{I_{x} \sigma_{y} / y_{\max }}=1-p .
$$

The following can be obtained from Equations (8b), (9b), and (10b):

$$
\phi_{1}=\frac{\Phi}{\Phi_{y}}=\frac{M / E_{0} I_{x}}{M_{y} / E_{0} I_{x}}=\frac{M}{M_{y}}=1-p .
$$

4.2. Single-Sided Plastic Distribution. With the increase of bending moment, the cross section of the member comes into the single-sided plastic distribution, and the stress distribution of the section is shown in Figure 12(d). In the figure, $y_{1}$ and $-y_{1}$ are the ordinates of the outer edges of the upper and lower flanges of $\mathrm{H}$-shaped cross section, respectively. $y_{1}=H_{1 / 2} \cdot y_{2}$ and $-y_{2}$ are the ordinates of the inner edges of the upper and lower flanges of $\mathrm{H}$-shaped cross section, respectively. $y_{2}=H_{1 / 2} . y_{3}$ is the ordinate of the junction of the plastic zone and the elastic zone at the upper end of the cross section. In this case, the ultimate stress state of the section is that the tensile side edge of the cross section reaches the yield stress $\sigma_{\mathrm{y}}$.

When the bending moment $M$ is lower than a certain value, the plastic zone is in the cross section of the upper flange; that is, $y_{1} \geq y_{3} \geq y_{2}$. When the bending moment $M$ is higher than a certain value, the plastic zone exceeds the cross section of the upper flange; that is, $0<y_{3}<y_{2}$.

According to the coordinates $N\left(-f_{y}, y_{3}\right)$ and $M\left(f_{y},-y_{1}\right)$ of the two endpoints of the stress curve in the elastic area, the stress equation $\sigma_{\mathrm{z}}=f(y)$ in the elastic area can be obtained as follows:

$$
\sigma_{z}=-\frac{2 f_{y}}{y_{1}+y_{3}} y+f_{y} \frac{y_{3}-y_{1}}{y_{1}+y_{3}} .
$$

$K$ is defined by

$$
K=-\frac{2 f_{y}}{y_{1}+y_{3}} .
$$

$C$ is defined by

$$
C=f_{y} \frac{y_{3}-y_{1}}{y_{1}+y_{3}}
$$

When $y_{3}=y_{2}$, the following can be obtained from Equations (7a), (8c), (9c), and (11):

$$
p=\frac{P}{P_{\mathrm{y}}}=\frac{\int_{A} \sigma_{\mathrm{z}} d A}{A\left(-f_{\mathrm{y}}\right)}=\frac{B t_{\mathrm{f}}^{2}+t_{\mathrm{f}} t_{\mathrm{w}} H_{1}}{A\left(H-t_{\mathrm{f}}\right)} .
$$

When $0 \leq p \leq B t_{f}^{2}+t_{\mathrm{f}} t_{\mathrm{w}} H_{1} / A\left(H-t_{\mathrm{f}}\right)$ and $y_{1} \geq y_{3} \geq y_{2}$, the following can be obtained from Equations (7a), (8c), (9c), and (11):

$$
p=\frac{P}{P_{y}}=\frac{\int_{A} \sigma_{z} d A}{A\left(-f_{y}\right)}=\frac{B \int_{y_{3}}^{y_{1}}\left(-f_{y}\right) d y+B \int_{y_{2}}^{y_{3}}(K y+C) d y+t_{w} \int_{-y_{2}}^{y_{2}}(K y+C) d y+B \int_{-y_{1}}^{-y_{2}}(K y+C) d y}{A\left(-f_{y}\right)},
$$

and then

$$
\mathrm{By}_{3}^{2}+\left(p A-2 B_{1} H_{1}\right) y_{3}+J=0 \text {. }
$$

We have $J=0.5 p A H-0.25 B H^{2}+H H_{1} B_{1}$.

The following can be obtained from Equations (7b), (8a), (10a), and (11):

$$
m_{2}=\frac{\int_{A} y \sigma_{z} d A}{I_{x} \sigma_{y} / y_{\max }}=\frac{2 t_{w} H_{1}^{3} H-B H\left(4 y_{3}^{3}+2 H_{1}^{3}-H^{3}-3 H^{2} y_{3}\right)}{12\left(2 y_{3}+H\right) I_{x}} .
$$
(9b):

The following can be obtained from Equations (8b) and

$$
\phi_{2}=\Phi_{2} / \Phi_{y}=\frac{M / E_{0} I_{x}}{M_{y} / E_{0} I_{x}}=m_{2}
$$

and when $B t_{f}^{2}+t_{f} t_{w} H_{1} / A\left(H-t_{f}\right) \leq p<1 \quad$ and $-y_{1}<y_{3} \leq y_{2}$, the following can be obtained from Equations $(7 \mathrm{a}),(8 \mathrm{c}),(9 \mathrm{c})$, and (11):

$$
p=\frac{P}{P_{y}}=\frac{\int_{A} \sigma_{z} d A}{A\left(-f_{y}\right)}=\frac{B \int_{y_{2}}^{y_{1}}\left(-f_{y}\right) d y+t_{w} \int_{y_{3}}^{y_{2}}\left(-f_{y}\right) d y+t_{w} \int_{y_{2}}^{y_{3}}(K y+C) d y+B \int_{-y_{1}}^{-y_{2}}(K y+C) d y}{A\left(-f_{y}\right)},
$$

and then

$$
t_{w} y_{3}^{2}+p A y_{3}+G=0,
$$

where $G=-0.5 H_{1} t_{\mathrm{w}}\left(t_{\mathrm{f}}+0.5 H\right)-B t_{f}^{2}+0.5 p A H$.

The following can be obtained from Equations (7b), (8a), (9a), and (11):

$$
\begin{aligned}
m_{2} & =\frac{\int_{A} y \sigma_{z} d A}{I_{x} \sigma_{y} / y_{\max }} \\
& =\frac{\left(3 H_{1}^{2} y_{3}+H_{1}^{3}-4 y_{3}^{3}\right) t_{w} H+B H\left(3 y_{3}\left(H^{2}-H_{1}^{2}\right)+H^{3}-H_{1}^{3}\right)}{12\left(2 y_{3}+H\right) I_{x}},
\end{aligned}
$$


and when the outer edge of the upper flange reaches a strain of $-1.6 \%$, the following can be obtained:

$$
y_{3}=-0.29 H-0.21 t_{f} \text {. }
$$

By substituting Equation (22) into Equation (17), we obtain the following equation:

$$
p=\frac{B t_{\mathrm{f}}^{2}+0.5 H_{1} t_{\mathrm{w}}\left(t_{\mathrm{f}}+0.5 H\right)-t_{\mathrm{w}}\left(0.29 H+0.21 t_{f}\right)^{2}}{0.21 A\left(H-\mathrm{t}_{\mathrm{f}}\right)} .
$$

$Q$ is defined by

$$
Q=\frac{B t_{f}^{2}+0.5 H_{1} t_{w}\left(t_{f}+0.5 H\right)-t_{w}\left(0.29 H+0.21 t_{f}\right)^{2}}{0.21 A\left(H-t_{f}\right)},
$$

and when $B t_{f}^{2}+t_{\mathrm{f}} t_{\mathrm{w}} H_{1} / A\left(H-t_{\mathrm{f}}\right) \leq p \leq \mathrm{Q},-\left(0.29 H+0.21 t_{\mathrm{f}}\right)$ $\leq y_{3} \leq y_{2}$, the cross-sectional damage is general damage, and the following can be obtained from Equations (5), (8b), and (9b) as follows:

$$
\begin{aligned}
\phi_{2} & =\frac{M / E_{1} I_{x}}{M_{y} / E_{0} I_{x}} \\
& \approx \frac{A}{A-0.03268 t_{w} H 0.5 H-y_{3}+0.01634 B t_{f} 3 H-2 y_{3} / H+2 y_{3}} m_{2},
\end{aligned}
$$

and when $\mathrm{Q} \leq p \leq 1,-y_{1} \leq y_{3} \leq-\left(0.29 H+0.21 t_{f}\right)$, generally damaged area and seriously damaged area can be found in the sectional damage zone. The following can be obtained from Equations (6), (8b), and (9b):

$\varphi_{2} \approx \frac{A m_{2}}{A-\left\{115.2\left[B t_{\mathrm{f}}+t_{\mathrm{W}}\left(H / 2-t y_{4}\right)\right]+77 t_{\mathrm{W}}\left(y_{4}-y_{3}\right)+2.66 B t_{\mathrm{f}} 3 H-2 f_{3} / H+2 y_{3}+1.33 t_{\mathrm{W}} H_{1}+4.71 H-2 y_{3} / H+2 y_{3}\left(H_{1}-2 y_{4}\right)\right\} \times 10^{-3}}$,

where $y_{4}=1.855 H+4.71 y_{3} ; y_{4}$ is the ordinate at the junction of the generally damaged area and the seriously damaged area of the cross section; that is, the ordinate of the sectional strain is $-1.6 \%$.

4.3. Double-Sided Plastic Distribution. With the increase of bending moment limit, the cross section of the member comes into the double-sided plastic distribution, and the stress distribution of the cross section is shown in Figure 12(e). Here, the ultimate stress state of the cross section is the full-sectional yield, and the cross-sectional bending moment $M$ reaches the ultimate bending moment $M_{\mathrm{pc}}$.
When $y_{3}=-y_{2}$, the following can be obtained from Equations (7a), (8c), and (9c):

$$
p=\frac{H_{1} t_{w}}{A}
$$

and when $0 \leq p \leq H_{1} t_{w} / A$ and $-y_{2} \leq y_{3} \leq 0$, the following can be obtained from Equations (7a), (8c), and (9c):

$$
m_{p c} \approx 1.5\left(1-\frac{A^{2} H}{12 t_{w} I_{x}} p^{2}\right) \text {. }
$$

The following can be obtained from Equations (7a), (8a), and $(9 c)$ :

$$
m_{p c}=\frac{M_{p c}}{M_{y}}=\frac{\int_{A} y \sigma_{z} d A}{I_{x} \sigma_{y} / y_{\max }}=\frac{B \int_{y_{2}}^{y_{1}} y\left(-f_{y}\right) d y+t_{w} \int_{y_{3}}^{y_{2}} y\left(-f_{y}\right) d y+t_{w} \int_{-y_{2}}^{y_{3}} y f_{y} d y+B \int_{-y_{1}}^{-y_{2}} y f_{y} d y}{I_{x}\left(-f_{y}\right) / y_{1}} .
$$

Substituting Equation (28) into the above equation, we can obtain

$$
m_{\mathrm{pc}} \approx 1.5\left(1-\frac{A^{2} H}{12 t_{\mathrm{w}} I_{\mathrm{x}}} p^{2}\right)
$$

$$
y_{3}=\frac{H_{1} t_{w}-p A}{2 B}-0.5 H_{1}
$$

The following can be obtained from Equations (7a), (8a), and $(9 a)$ :

and when $H_{1} t_{\mathrm{w}} / A \leq p \leq 1$ and $-y_{1} \leq y_{3} \leq-y_{2}$, the following can be obtained from Equations (7a), (8c), and (9c):

$$
m_{p c}=\frac{M_{p c}}{M_{y}}=\frac{B \int_{y_{2}}^{y_{1}} y\left(-f_{y}\right) d y+t_{w} \int_{-y_{2}}^{y_{2}} y\left(-f_{y}\right) d y+B \int_{y_{3}}^{-y_{2}} y\left(-f_{y}\right) d y+B \int_{-y_{1}}^{-y_{3}} y f_{y} d y}{I_{x}\left(-f_{y}\right) / y_{1}}=\frac{B\left(H^{3} / 8+y_{3}^{2}\right)}{I_{x}} .
$$


After summarizing the above equations, the calculation expressions of $M-\Phi-P$ of $\mathrm{H}$-section steel members can be obtained, as shown in Table 2.

However, the elastic modulus $E$ and yield strength $y$ of the damaged $\mathrm{H}$-shaped cross section are different from those of undamaged cross section, but above $m_{1}, m_{2}, m_{\mathrm{pc}}, \phi_{1}$, and $\phi_{2}$ are dimensionless variables. Whether undamaged or damaged cross section, $E$ and $\sigma_{\mathrm{y}}$ can be eliminated in the derivation. Hence, the above derivation and results are applicable to the undamaged and damaged cross sections of the $\mathrm{H}$-shaped steel members.

\section{Approximate Equations of $M-\Phi-P$ for H-Section Steel Members}

The cross-sectional sizes of test steel columns are as follows [24]: $H=125.43 \mathrm{~mm}, \quad H_{1}=113.09 \mathrm{~mm}, \quad B=124.88 \mathrm{~mm}$, $B_{1}=59.45 \mathrm{~mm}, t_{\mathrm{f}}=5.98 \mathrm{~mm}, t_{\mathrm{w}}=6.17 \mathrm{~mm}, A=2,217 \mathrm{~mm}^{2}$, and $I_{\mathrm{x}}=6.21 \times 10^{6} \mathrm{~mm}^{4}$ were analyzed. From the equations in Table 2, the dimensionless parameters of the cross section under various loading conditions can be obtained as shown in Table 3.

Considering the damage of member cross section, the relationships between $m_{2}, \phi_{2}, m_{\mathrm{pc}}$, and $p$ in Table 2 are plotted as correlation curves, as shown in Figure 13. By fitting the curves in Figure 13 with numerical analysis method, the approximate expressions of $M-\Phi-P$ for $H$-section steel members can be obtained, as shown in Table 4 .

\section{Deformation Analysis of Damaged Steel Member}

Once the $M-\Phi-P$ relationship of the cross section of damaged steel member is established, the deformation analysis of the member can be carried out. The Newmark method [22] and its derivative methods are widely used in beam-column analysis. This method is especially effective in solving the maximum bearing capacity of beam column under loads in the elastic or elastic-plastic range.

The data of steel column test [24] is used, the cross section is $H 125 \times 125 \times 6 \times 6 \mathrm{~mm}$, and the steel material is Q345. The column is $1.02 \mathrm{~m}$ high, subjected to eccentric load with fixed ends, and the loading scheme and photograph of steel column test are shown in Figures 14 and 15. The experimental specimen was simulated by a finite element software, ABAQUS. The constitutive model of Q345 steel is based on the tensile test results. S4R element (4-node general-purpose shell element) was used for meshing steel. The failure mode of the column in ABAQUS model was consistent with the test result, as shown in Figure 16.

The specific calculation process of the steel column deformation using the Newmark method [22] is as follows:

(1) The steel column was divided into four equal parts, and the number of each piecewise point is shown in Figure 17.

(2) During the test, the steel column was loaded twice, and the steel column reached the ultimate bearing capacity for each loading. The residual deformation
TABle 2: Calculation expressions of M- $\Phi-\mathrm{P}$ of $\mathrm{H}$-section steel members.

\begin{tabular}{|c|c|c|}
\hline $\begin{array}{l}\text { Dimensionless } \\
\text { variable }\end{array}$ & Range of $P$ & Equation \\
\hline$m_{1}$ & $0 \leq p \leq 1$ & $\begin{array}{l}\text { Equation } \\
\text { (10b) }\end{array}$ \\
\hline$\phi_{1}$ & $0 \leq p \leq 1$ & $\begin{array}{l}\text { Equation } \\
\text { (10c) }\end{array}$ \\
\hline \multirow{2}{*}{$m_{2}$} & $0 \leq p \leq B t_{f}^{2}+t_{\mathrm{f}} t_{\mathrm{w}} H_{1} / A\left(H-t_{\mathrm{f}}\right)$ & $\begin{array}{l}\text { Equation } \\
\quad(14)\end{array}$ \\
\hline & $B t_{f}^{2} t_{f} t_{w} H_{1} / A\left(H-t_{1}\right) \leq p \leq 1$ & $\begin{array}{l}\text { Equation } \\
\quad(17)\end{array}$ \\
\hline \multirow{3}{*}{$\phi_{2}$} & $0 \leq p \leq B t_{f}^{2}+t_{\mathrm{f}} t_{\mathrm{w}} H_{1} / A\left(H-t_{\mathrm{f}}\right)$ & $\begin{array}{l}\text { Equation } \\
\quad(15)\end{array}$ \\
\hline & $B t_{f}^{2} t_{f} t_{w} H_{1} / A\left(H-t_{1}\right) \leq p \leq Q$ & $\begin{array}{l}\text { Equation } \\
\quad(19)\end{array}$ \\
\hline & $Q \leq p \leq 1$ & $\begin{array}{l}\text { Equation } \\
\quad(20)\end{array}$ \\
\hline \multirow[b]{2}{*}{$m_{\mathrm{pc}}$} & $Q \leq p \leq H_{1} t_{w} / A$ & $\begin{array}{l}\text { Equation } \\
\quad(23)\end{array}$ \\
\hline & $H_{1} t_{w} / A \leq p \leq 1$ & $\begin{array}{l}\text { Equation } \\
\quad(25)\end{array}$ \\
\hline
\end{tabular}

TABLE 3: Dimensionless parameters of steel column cross sections.

\begin{tabular}{lccccc}
\hline$P$ & $m_{1}$ & $\phi_{1}$ & $m_{2}$ & $\phi_{2}$ & $m_{\mathrm{pc}}$ \\
\hline 0 & 1 & 1 & 1.000 & 1.000 & 1.500 \\
0.1 & 0.9 & 0.9 & 1.035 & 1.046 & 1.480 \\
0.2 & 0.8 & 0.8 & 1.002 & 1.025 & 1.418 \\
0.3 & 0.7 & 0.7 & 0.920 & 0.966 & 1.316 \\
0.4 & 0.6 & 0.6 & 0.804 & 0.876 & 1.165 \\
0.5 & 0.5 & 0.5 & 0.675 & 0.759 & 0.985 \\
0.6 & 0.4 & 0.4 & 0.543 & 0.632 & 0.763 \\
0.7 & 0.3 & 0.3 & 0.411 & 0.496 & 0.608 \\
0.8 & 0.2 & 0.2 & 0.279 & 0.349 & 0.411 \\
0.9 & 0.1 & 0.1 & 0.147 & 0.191 & 0.208 \\
1 & 0 & 0 & 0 & 0 & 0 \\
\hline
\end{tabular}

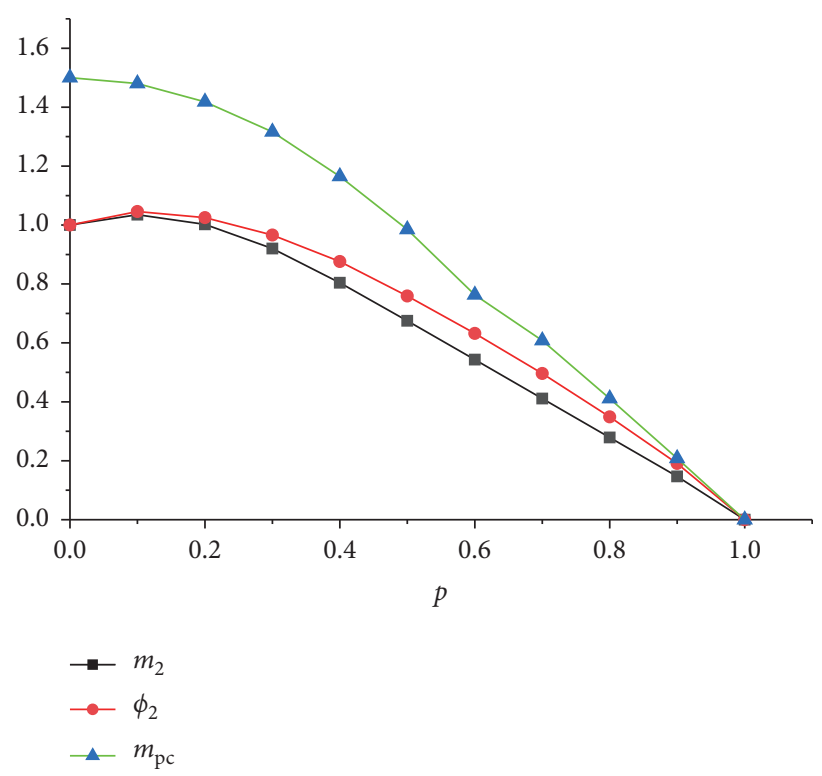

FIgURE 13: Correlation curves between $(\mathrm{m})_{2}, \phi_{2},(\mathrm{~m})_{\mathrm{pc}}$ and $(\mathrm{p})$ of column sections. 
Table 4: Approximate expressions of M- $\Phi-P$ relationship of steel column sections.

\begin{tabular}{lcc}
\hline & $0 \leq p \leq 0.4$ & $0.4 \leq p \leq 1$ \\
\hline$m_{1}$ & & $1-p$ \\
$\phi_{1}$ & $1.003+0.496 p-2.51 p^{2}$ & $1.333(1.006-p)$ \\
$m_{2}$ & $1.004+0.558 p-2.214 p^{2}$ & $1-p$ \\
$\phi_{2}$ & $1.5-2.1 p^{2}$ & $1.191-0.534 p-0.651 p^{2}$ \\
$m_{\mathrm{pc}}$ & & $1.929(1.007-p)$ \\
\hline
\end{tabular}

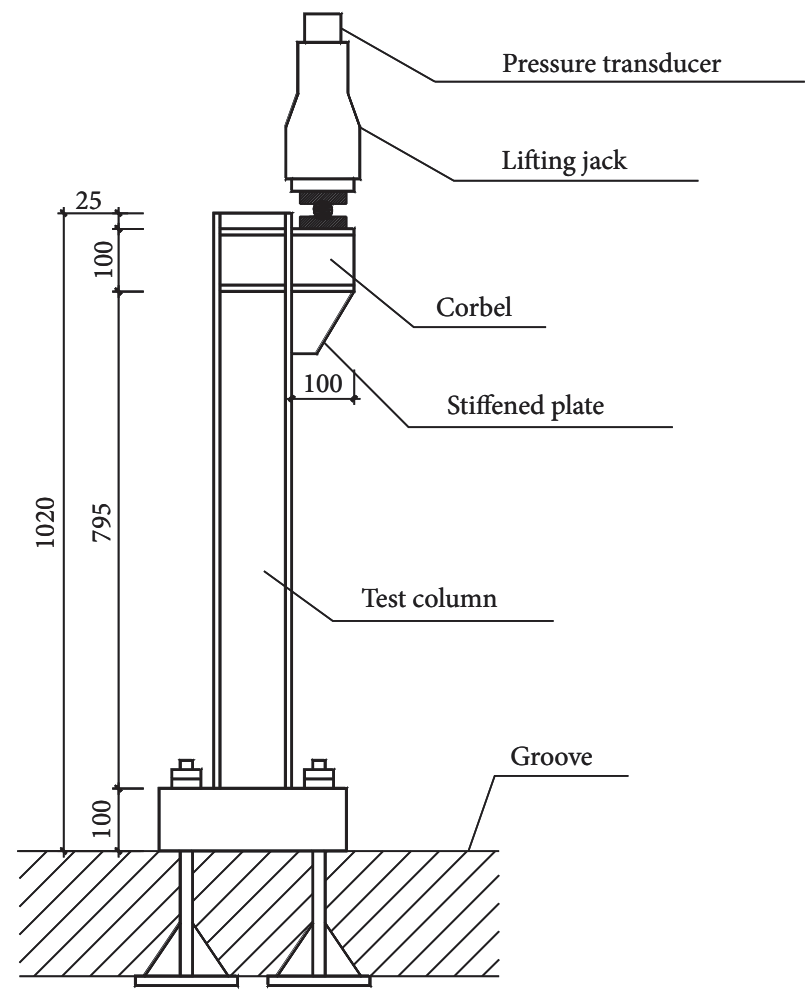

FIgURE 14: Schematic diagram of the loading setup.

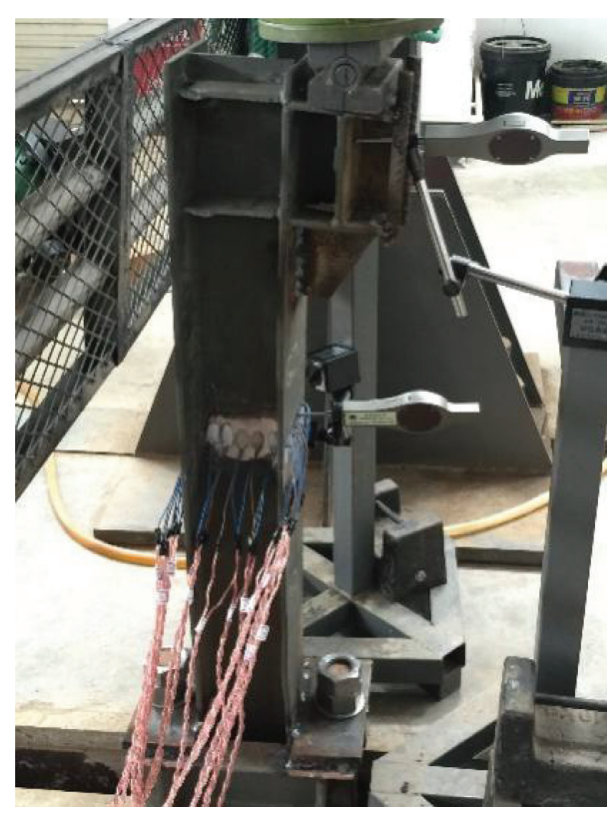

FIGURE 15: Photograph of the loading setup. 


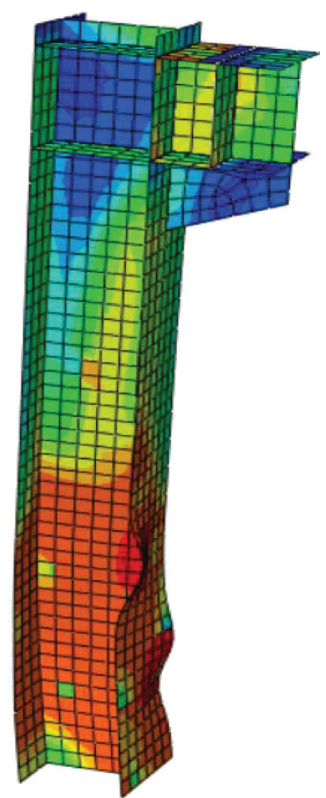

(a)

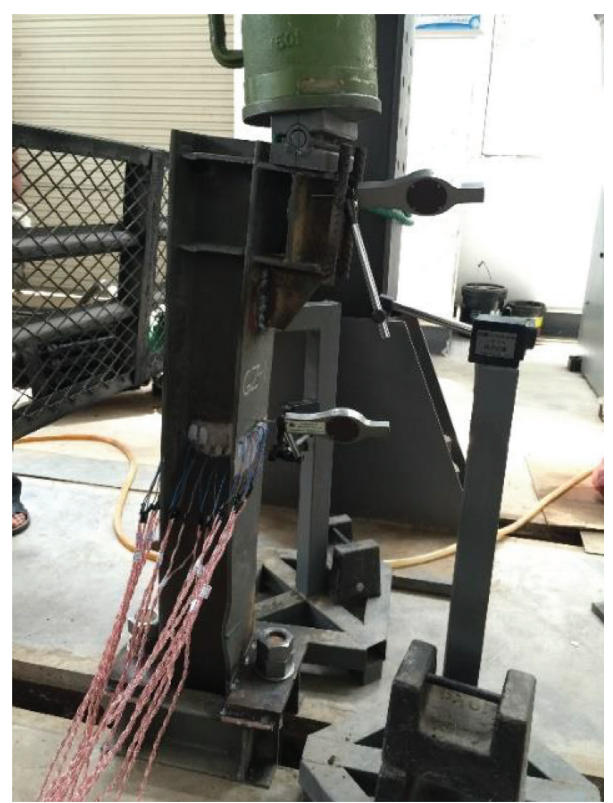

(b)

FIGURE 16: Comparison of failure mode. (a) Failure mode of finite element model. (b) Failure mode of the specimen.

\begin{tabular}{|lllllllll} 
& $L / 4$ & & $L / 4$ & & $L / 4$ & & $L / 4$ &
\end{tabular}

Figure 17: Piecewise points of steel column.

of the steel column at each piecewise point after the first loading was taken as the initial defect value $v_{0 \mathrm{k}}$ in the calculation of the steel column, $k=0 \sim 4$, and the deformation values of the piecewise points under the axial force and the moment are assumed.

(3) Calculate the bending moment $M_{k}$ of each piecewise point, $k=0 \sim 4$ :

$$
M_{k}=M_{1}+P\left(v_{k}+v_{0 k}\right),
$$

where $M_{1}$ is the first-order bending moment generated by loads and $P_{v k}$ is the second-order bending moment caused by $P-\delta$ effect.

(4) According to the known bending moment-curvatu re-axial force relationship of the cross section, calculate the curvature $\Phi_{k}$ of each piecewise point, $k=0 \sim 4$.

(5) A new group of piecewise point displacement values of the steel column was calculated by using the conjugate beam method, and the curvature distribution between the piecewise points was assumed to be distributed according to the characteristics of Figure 18. The equivalent nodal loads were calculated by using the equations given in Figure 18. The equations in Figure 18(a) should be used if the piecewise point is an endpoint or the curvature of the point suddenly changes due to the sudden change of $M$ or $E I$ at the piecewise point. The resulting nodal loads were used as the loads of the conjugate beam to calculate the shear force and bending moment of the conjugate beam. At this time, the shear force and bending moment are equivalent to the slope and deflection of the real beam.

(6) Compare the deflections calculated in step 5 with the deflections assumed in step 2. If the difference can be neglected, then the solution is considered to be obtained. Otherwise, take the calculated deflections as a new group of hypothetical deflections, and repeat steps 3 to 5 until convergence.

By using this method, the deformations of damaged steel columns under the effect of each test load after secondary loading are calculated, respectively. Table 5 shows the calculation results of deformations of the steel columns when the axial pressure is $150 \mathrm{kN}$ and $260 \mathrm{kN}$.

Table 6 shows the test results, theoretical results, and FEM results of damaged steel columns at different load levels.

Table 6 indicates that the relative errors between the test results and the theoretical results under five levels of loads are within $10 \%$. The test results, theoretical results, and FEM results of load-displacement curves of damaged steel columns under secondary loading are shown in Figure 19.

The analysis above shows that the theoretical calculation method for damaged steel columns used in this study is in good agreement with the test results. 


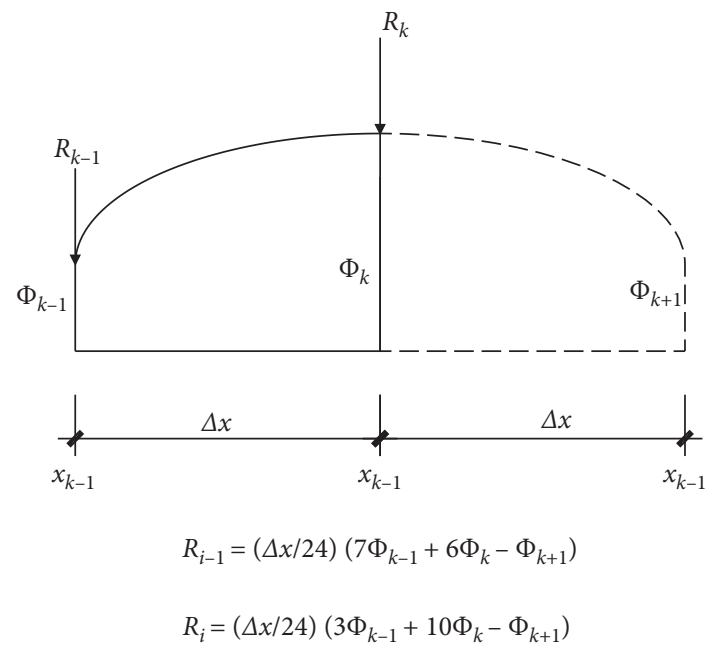

(a)
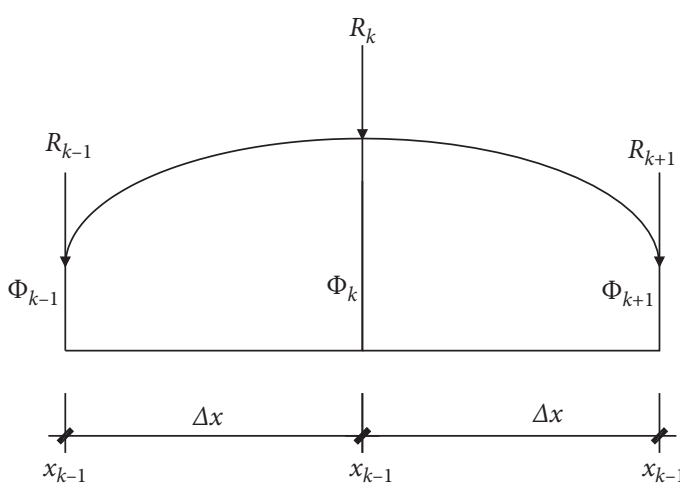

$R_{i}=(\Delta x / 12)\left(\Phi_{k-1}+10 \Phi_{k}+\Phi_{k+1}\right)$

(b)

FIgURE 18: Equivalent nodal loads.

TABLE 5: Deformation calculations of steel columns.

\begin{tabular}{lcccccccccc}
\hline Load & \multicolumn{4}{c}{$P=150 \mathrm{kN}, p=0.19$} & \multicolumn{5}{c}{$P=260 \mathrm{kN}, p=0.34$} \\
Piecewise point & 0 & 1 & 2 & 3 & 4 & 0 & 1 & 2 & 3 & 4 \\
\hline Initial moment $M_{1}$ & 0.43 & 0.43 & 0.43 & 0.43 & 0.43 & 0.75 & 0.75 & 0.75 & 0.75 & 0.75 \\
Initial imperfection $v_{0 \mathrm{k}}$ & 0 & 0.0072 & 0.0144 & 0.0235 & 0.0325 & 0 & 0.0072 & 0.0144 & 0.0235 & 0.0325 \\
Assuming additional deflection $v_{k}$ & 0 & 0.000687 & 0.00248 & 0.00528 & 0.00897 & 0 & 0.002 & 0.0068 & 0.0137 & 0.0224 \\
Moment of $P-\delta$ & 0.00802 & 0.00649 & 0.00475 & 0.00245 & 0 & 0.0187 & 0.0155 & 0.0115 & 0.006 & 0 \\
Changing common factor & 0.179 & 0.145 & 0.106 & 0.0547 & 0 & 0.416 & 0.346 & 0.256 & 0.134 & 0 \\
Total moment $M_{k}$ & 0.610 & 0.576 & 0.537 & 0.486 & 0.431 & 1.166 & 1.096 & 1.006 & 0.884 & 0.75 \\
$M$ - $\Phi-P$ relationship $\Phi_{k}$ & 0.665 & 0.611 & 0.553 & 0.496 & 0.431 & 2.055 & 1.512 & 1.178 & 0.960 & 0.755 \\
$R_{k}$ & 0.379 & 0.610 & 0.553 & 0.495 & 0.262 & 1.108 & 1.530 & 1.188 & 0.961 & 0.475 \\
$\theta_{k}$ & 0.379 & 0.989 & 1.543 & 2.038 & 1.108 & 2.638 & 3.826 & 4.787 & \\
$v_{k}$ & 0 & 0.379 & 1.368 & 2.911 & 4.949 & 0 & 1.108 & 3.746 & 7.572 & 12.359 \\
Calculating additional deflection $v_{\mathrm{k}}^{(1)}$ & 0 & 0.00069 & 0.00248 & 0.00528 & 0.00897 & 0 & 0.002 & 0.00678 & 0.0137 & 0.0224 \\
\hline
\end{tabular}

TABle 6: Comparison of horizontal displacements at the top of columns.

\begin{tabular}{lccccc}
\hline \multirow{2}{*}{ Load $(\mathrm{kN})$} & Test result $(\mathrm{mm})$ & Theoretical result $(\mathrm{mm})$ & $\begin{array}{c}\text { Displacement }(\mathrm{mm}) \\
\text { Relative error }(\%)\end{array}$ & FEM result (mm) & Relative error $(\%)$ \\
\hline 260 & 20.80 & 22.40 & 7.69 & 17.59 & 18.25 \\
240 & 17.98 & 17.10 & 5.15 & 15.39 & 16.83 \\
210 & 14.30 & 13.40 & 6.29 & 11.16 & 9.49 \\
180 & 12.07 & 10.90 & 9.69 & 9.31 \\
150 & 9.91 & 8.97 & 9.48 & 6.15 \\
\hline
\end{tabular}




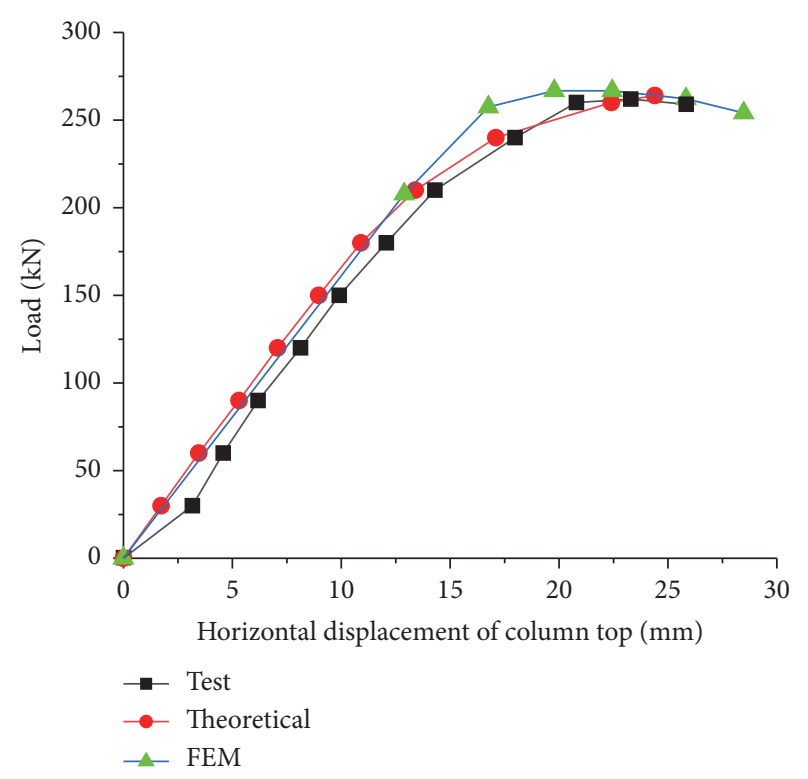

Figure 19: Comparison of load-displacement curves of steel columns under secondary loading.

\section{Conclusions}

According to the above analysis, the main conclusions are drawn as follows:

(1) The average elastic modulus is used to consider the effect of different degrees of damage on the mechanical properties of $\mathrm{H}$-shaped cross section. The damage of $\mathrm{H}$-shaped cross sections is divided into three levels: slight damage, general damage, and serious damage. The calculation equations of average elastic moduli under different degrees of damage are derived.

(2) By using the cross-sectional analysis method, the equations for calculating $M-\Phi-P$ relationships of damaged $\mathrm{H}$-section steel members are derived. According to the calculations of actual sections, the approximate equations for calculating $M-\Phi-P$ relationships of $\mathrm{H}$-section steel members are fitted.

(3) The Newmark method is used to analyze the deformations of damaged steel columns, and the results are in good agreement with the test results. The equations and method derived in this study have high accuracy and can be applied to the calculation of $M-\Phi-P$ relationships and deformations of damaged steel members.

\section{Data Availability}

The data used to support the findings of this study are available from the corresponding author upon request.

\section{Conflicts of Interest}

The authors declare that they have no conflicts of interest.

\section{Acknowledgments}

This work was supported by the Natural Science Foundation of Hunan Province of China (2020JJ4943) and Science and Technology Program of Hunan Housing and Urban Rural Development Department (KY202002).

\section{References}

[1] M. Ge, E. M. Lui, and A. C. Khanse, "Non-proportional damage identification in steel frames," Engineering Structures, vol. 32, no. 2, pp. 523-533, 2010.

[2] E. Görl and M. Link, "Damage identification using changes of eigenfrequencies and mode shapes," Mechanical Systems and Signal Processing, vol. 17, no. 1, pp. 103-110, 2003.

[3] B. V. Fell, A. T. Myers, G. G. Deierlein et al., "Testing and simulation of ultra-low cycle fatigue and fracture in steel braces," in Proceedings of the 8th U.S. National Conference on Earthquake Engineering, San Francisco, California, April 2006.

[4] H. Guo, B. Sun, and Z. Li, "Multi-scale fatigue damage model for steel structures working under high temperature," Acta Mechanica Sinica, vol. 35, no. 3, pp. 615-623, 2019.

[5] A. C. Neves, F. M. F. Simões, and A. Pinto da Costa, "Vibrations of cracked beams: discrete mass and stiffness models," Computers \& Structures, vol. 168, pp. 68-77, 2016.

[6] A. C. Altunışık, F. Y. Okur, and V. Kahya, "Modal parameter identification and vibration based damage detection of a multiple cracked cantilever beam," Engineering Failure Analysis, vol. 79, pp. 154-170, 2017.

[7] S. S. B. Chinka, B. Adavi, and S. R. Putti, "Influence of crack on modal parameters of cantilever beam using experimental modal analysis," Journal of Modeling and Simulation of Materials, vol. 1, pp. 16-23, 2018.

[8] D. Tao, C. Mao, D. Zhang, and H. Li, "Experimental validation of a signal-based approach for structural earthquake damage detection using fractal dimension of time frequency feature," Earthquake Engineering and Engineering Vibration, vol. 13, no. 4, pp. 671-680, 2014.

[9] Q.-R. Yue, Y. Zheng, X. Chen, and X.-G. Liu, "Research on fatigue performance of CFRP reinforced steel crane girder," Composite Structures, vol. 154, pp. 277-285, 2016.

[10] T. Tominaga, K. Matsuoka, Y. Sato, and T. Suzuki, "Fatigue improvement of weld repaired crane runway girder by ultrasonic impact treatment," Welding in the World, vol. 52, no. 12, pp. 50-62, 2008.

[11] Le Shen, M. Ding, F. Chen et al., "Experimental study on the cumulative damage constitutive model of high-performance steel Q345GJ under cyclic loading," Journal of Constructional Steel Research, vol. 181, 2021.

[12] F. Yang, M. Veljkovic, and Y. Liu, "Ductile damage model calibration for high-strength structural steels," Construction and Building Materials, vol. 263, 2020.

[13] T. Rabczuk and T. Belytschko, "Cracking particles: a simplified meshfree method for arbitrary evolving cracks," International Journal for Numerical Methods in Engineering, vol. 61, no. 13, pp. 2316-2343, 2010.

[14] T. Rabczuk, G. Zi, S. Bordas, and H. Nguyen-Xuan, "A geometrically non-linear three-dimensional cohesive crack method for reinforced concrete structures," Engineering Fracture Mechanics, vol. 75, no. 16, pp. 4740-4758, 2008.

[15] H. H. luo and D. Ai, "Mechanical impedance-based technique for steel structural corrosion damage detection," Measurement, vol. 88, pp. 353-359, 2016. 
[16] S. Hosseini, A. Heidarpour, F. Collins, and C. R. Hutchinson, "Effect of strain ageing on the mechanical properties of partially damaged structural mild steel," Construction and Building Materials, vol. 77, pp. 83-93, 2015.

[17] M. Momeni, "Damage evaluation of H-section steel columns under impulsive blast loads via gene expression programming," Engineering Structures, vol. 219, 2020.

[18] M. Momeni, M. A. Hadianfard, C. Bedon, and A. Baghlani, "Numerical damage evaluation assessment of blast loaded steel columns with similar section properties," Structures, vol. 20, pp. 189-203, 2019.

[19] J. Lemaitre, "Damage mechanics tutorial," NI Jin-Gang, TAO Chang-Chun, Translated, Science Press, Beijing, China, (in Chinese), 1996.

[20] Y. YANG, Study on Mechanical Behavior of Damaged Steel Frame Structure, Central South University of Forestry and Technology, Changsha, China, (in Chinese), 2014.

[21] L. O. N. G. Yu-qiu and S.-hua BAO, Structural Mechanics, Higher Education Press, Beijing, China, [in Chinese], 2018.

[22] W. F. Chen and E. M. Lui, Stability Design of Steel Frames, CRC Press, Boca Raton, Florida, USA, 1991.

[23] Q.-shan FAN, Ya-jun YIN, and J.-ling TANG, Material Mechanics, Tsinghua University Press, Beijing, China, [in Chinese], 2015.

[24] Yu-xuan XIANG, Study on Mechanical Properties of Damaged Steel Beam and Column, Central South University of Forestry and Technology, Changsha, China, [in Chinese], 2017. 